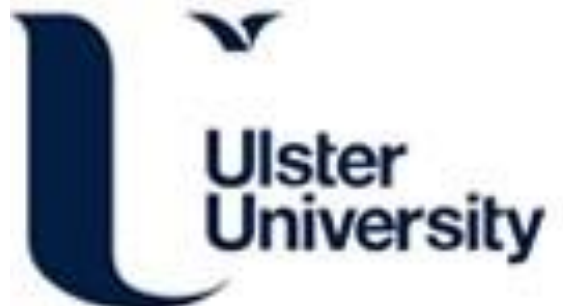

\section{The Designers Leap: Boundary Jumping to foster interdisciplinarity between Textile Design and Science}

Coulter, J. (2018). The Designers Leap: Boundary Jumping to foster interdisciplinarity between Textile Design and Science. Journal of Textile Design Research and Practice. https://doi.org/10.1080/20511787.2018.1451211

Link to publication record in Ulster University Research Portal

Published in:

Journal of Textile Design Research and Practice

Publication Status:

Published online: 16/07/2018

DOI:

10.1080/20511787.2018.1451211

\section{Document Version}

Author Accepted version

\section{General rights}

Copyright for the publications made accessible via Ulster University's Research Portal is retained by the author(s) and / or other copyright owners and it is a condition of accessing these publications that users recognise and abide by the legal requirements associated with these rights.

\section{Take down policy}

The Research Portal is Ulster University's institutional repository that provides access to Ulster's research outputs. Every effort has been made to ensure that content in the Research Portal does not infringe any person's rights, or applicable UK laws. If you discover content in the Research Portal that you believe breaches copyright or violates any law, please contact pure-support@ulster.ac.uk. 


\title{
The Designers Leap: Boundary Jumping to foster interdisciplinarity between Textile Design and Science
}

\author{
Janet Coulter \\ Belfast School of Art, Ulster University \\ Room BA003 012 \\ York Street \\ BELFAST \\ $B T 15$ 1ED \\ 02895367236 \\ im.coulter@ulster.ac.uk
}

\begin{abstract}
Creative thinking is an instinctive problem-solving process for designers however, designers alone cannot solve real-world problems. Collaboration between higher education and industry, and across design and science disciplines can create new paradigms of research to address societal and economic challenges. This paper argues from the perspective of fashion and textile designers, for design to be at the heart of the collaborative research process and advocates for co-design, speculative-design and scenario design to be considered as valid methodologies to foster interdisciplinarity. Perspectives on interdisciplinary partnerships across academic disciplines and with industry are typified by two very different reflections of collaborative projects between fashion designers, textile designers, scientists and industrial partners. The paper identifies commonalities and differences between scientists and designers, with particular relevance to textiles, in a bid to understand how they may collaborate more effectively in the context of interdisciplinary work, and the paper further identifies factors needed for establishing common enablers for engaging in co-design. This is an under-explored field and highlights the changing role of the designer, and as such is of value to researchers in textiles, fashion and product design.
\end{abstract}

\section{Keywords:}

Interdisciplinary; Transdisciplinary; Co-Design; Speculative Design; Boundary Jumping; Textiles; Fashion

\section{Introduction}

Creative thinking is part of an intuitive research and problem-solving process for designers however, designers' skills alone are not sufficient to address the emerging complex issues faced globally by industry and society. Over a decade ago both The Cox Review of Creativity in Business (Cox 2005) and Lord Sainsbury's Science and Innovation Policy Review (Sainsbury 2007) drew attention to the need for design and science disciplines to work in a more 
interdisciplinary way. Both reports highlighted the potential for synergies between higher education and industry, and yet more than a decade later there are still relatively few examples of successful collaboration. The paths of the textile designer and the engineer seldom cross within the textile industry (Morgan 2016) and although the need for multidisciplinary approaches is clear, there is a lack of literature around the field of textiles to demonstrate how disciplines might work together (Walker et al 2015). Speaking at MIT's Media Lab' 30th anniversary, Director Joi Ito proclaimed that "Connecting science and design is the future". He asserted that science, design, art, and engineering, can no longer be disciplines explored in isolation, and that through collaboration faster progress and new discovery can be made (Stinson 2016). A collaborative and innovative approach, encompassing many disparate fields of expertise has a greater prospect of delivering solutions to real-world problems and such approaches bring new opportunities for design and science disciplines to collaborate. This holds particular relevance in for the field of textile materials which has commonality to both the design and science, and Heimdal and Lenau (2010) note the effectiveness of textiles as a trigger across disciplines. Walker et al believe that the challenge of designing smart textiles creates unique opportunities to inform new design methodologies. Whilst collaborative approaches highlight the potential for synergies between higher education and industry, and offer significant opportunity to solve global challenges, interdisciplinary modes of working can often be fraught with tension and conflict between the respective stakeholders. The case studies presented in this paper highlight textiles as a common ground to which both science and design can relate to.

\section{The complexity of Interdisciplinary}

Interdisciplinarity (ID) is ambiguous in nature, and there is no absolute definition (Klein 2006). It is characterised by divergent thinking, encompassing distinct and often intersecting fields of expertise for the purpose of exploring differences and commonalities between disciplines. Discrete disciplines of textile and fashion design have almost become interdisciplinary in their own right. They have been ruptured and continue to be blurred, yielding to new hybrids of designers who comprise a blend of artists, engineers, designers and thinkers (Rodgers (2008). Managed well, interdisciplinarity can project its value well beyond the boundaries of traditional thinking of each discipline involved and create new solutions that exceed expectations. Klein (1996, p.1) asserts that "Crossing boundaries is a defining characteristic of our age" however, the fluidity of interdisciplinary methodologies and their numerous variables add layers of complexity to the research practice. Unpredictability is part of the process and this compounded by other unknown variables such as the diversity of academic backgrounds within the research team and the dynamics of the group. The purpose and end the beneficiary of the research are also impacting factors and this is often determined by whether industry is involved in the collaboration. Industrial collaboration implies that the inquiry will be driven by outcome and the 
end purpose of the partnership is commercial benefit. Conversely, curiosity driven projects tend to be more speculative and focused on future societal prosperity. The complex and possible permutations of the variables make interdisciplinary research (IDR) a risky strategy. The ambiguity surrounding the ID process means that it is not easily defined or understood, and its working practices can be particularly alien to scientists who favour well defined, prescriptive and quantifiable methodologies. Rust (2007) maintains that design researchers are not always able to clearly articulate their contribution to knowledge and he notes that this is particularly evident in interdisciplinary research. One contributor's research will catalyse or enable another's research in the group and these contributions do not necessarily have to be specifically articulated to make them acceptable. Rust argues that this should not necessarily diminish the validity of the research and suggests that participating researchers from disparate fields need to acknowledge each-others' contribution in developing new knowledge in order that everyone can claim ownership of its outcomes. Textile design provides a rich environment for collaborative practice and the development of technical textiles in recent years has played an interesting role in the context of interdisciplinarity, creating a common ground where both designer and scientist closely collaborate to realise new materials. As an illustrative example, a textile designer at Loughborough University (Morgan 2017) integrated her textile design practice with specialist scientific and technical knowledge through the use of laser technology, and in collaboration with industrial partners created unique techniques. As part of their research outcomes they found that interdisciplinary collaboration enables designers to immerse themselves in new processes, building innovative approaches to textile design which advances knowledge within the field, and they concluded that this could not have been achieved with a single disciplinary approach.

The risks associated with IDR mean that industrial partners are cautious in their involvement. In a review of the Landscape of Interdisciplinary Research, the National Endowment for Science, Technology and the Arts (NESTA), Blackwell et al (2010) argue that industry measures of impact do not take into account the value that creativity; curiosity, collegiality and serendipity can play in IDR. The review proposes other benchmarks of success such as recognition of new insights and intellectual capacity, and seeks to understand how a shared vision for research across disciplines, universities and industries can be realised. With no generic or widely accepted definition of 'interdisciplinarity' and no single model suited to all situations it is not surprising that many researchers shy away from the challenges of IDR. However, academics who choose to investigate real world challenges are more inclined to value the research of academics from other disciplines and as such, actively seek multidisciplinary, interdisciplinary, or transdisciplinary collaboration. Klein (1990, pg.196) perhaps offers the clearest definition of IDR as "a means of solving problems and answering questions that cannot be satisfactorily 
addressed using single methods or approaches". Huutoniemi (2010) contends that the way in which interdisciplinary research is labelled plays a significant part in how it is conceptualized and Bammer (2016) asserts that interdisciplinarity has become "a catch-all term" and that "lumping" IDR together makes it difficult to assess which modes are most effective. A number of researchers (Stember 1991; Gibbons et al 1994; Tress et al 2005; Klein 2006; Feller 2006; Jensensius 2012; Ito 2016) offer an array of labels and terms to distinguish types interdisciplinary research and drawing on the literature these can be summarized as follows: 
'intra'-disciplinary Working within one discipline

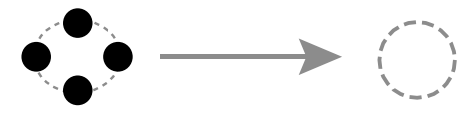

'anti'-disciplinary Working outside of any discipline

'cross'-disciplinary $\begin{aligned} & \text { One discipline considered from } \\ & \text { the perspective of another }\end{aligned}$

'multi'-disciplinary $\begin{aligned} & \text { Different disciplines utilising the } \\ & \text { knowledge of other disciplines }\end{aligned}$

'inter'-disciplinary $\begin{aligned} & \text { DIfferent discipline synthesising } \\ & \text { disciplinary knowledge and practice }\end{aligned}$

'trans'-disciplinary Co-creating new knowledge beyond disciplinary perspective to transcend disciplines

Key: Designers $\because \bigcirc \bigcirc$ Non Designers Knowledge

Table 1. Definitions of Modes of Research Practice 
When academic researchers collaborate with professionals and end users to co-create new knowledge and cultivate novel solutions to real world challenges, they can transcend their respective disciplines and become truly transdisciplinary (Tress et al. 2005; Klein 2015). This transformation is realised when researchers go beyond contributing their knowledge 'to' a group, and begin to work together 'as' a group with the participation of relevant external stakeholders. Their interconnecting knowledge, will result in the co-creation of extended new knowledge and a true transdisciplinary experience 'for' the group.

\section{Rationale for Interdisciplinarity}

The trend towards interdisciplinary working has continued to increase in line with the complexity of emerging global problems as designers strive to find new approaches to problem solving. A growing number of authors have contributed their views to the philosophical and scholarly consideration of interdisciplinary perspectives, in a bid to advance new knowledge and understanding (Walker 2011; Bruns 2013; Strang and McLeish, 2015). Textile designer BriggsGoode (2016) outlines her collaboration with research partners from computer science, health sciences and a mental health charity and acknowledges that although time can pose significant challenges in the co-design process, that other factors such as open communication and dialogue were key factors in the success of this textile-led interdisciplinary project. Although other authors allude to the exceptional challenges associated with sustaining IDR over a period of time (Hackett 2005; Shrum et al 2007), IDR has the potential to ignite a catalytic reaction and bring synthesis to a problem, achieving transformational outcomes that transcend the traditional boundaries of disciplinary silos and create new typologies of knowledge. However, the mere act of creating research groups across different disciplines will not automatically result in innovation. There is no formula for ensuring synthesis, but without it a project will have a limited chance of success, therefore it is essential to create an enabling environment for interdisciplinarity. First and foremost, there needs to be a clear raison d'être and commonality of purpose at the outset of the research. Acceptance in the fluidity of approaches, and an ability to compromise and shift perspectives and long held values are both essential, and a willingness to step outside of personal comfort zones to 'unlearn' traditional methods of practice is crucial. This paper argues that fashion and textile designers have the enabling skill set needed to catalyse and facilitate this approach. Characterised by their ability to think creatively, their capacity for vision and adaptability, fashion and textile designers' high tolerance to ambiguity enables them to engage with other academics in related and disparate fields, and to interact in the emerging landscape that intersects design and science. These attributes alongside their and problem solving skills and specialist knowledge of materials and 3D form, make fashion and textile designers a valuable asset in IDR to both academia and industry. 


\section{Design Thinking meets Science Thinking}

Design thinking is a tool to facilitate the research process and is concerned with the broader context of creative problem solving. It uses designers' intuition and 'Designerly Ways of Knowing' (Cross 2001) to enable a rich exploration and range of possible outcomes to create new market opportunities. Tim Brown, CEO of IDEO maintains that everyone has the capacity to think creatively, but he suggests that most tend to overlook this in favour of more traditional problem solving strategies (Brown and Wyatt 2010 p.33). Brown maintains that design thinking is not about finding the right answer, but rather it is about translating problems into opportunities. The value of visionary thoughts is that they enable designers to speculate about the future, transforming their inspirational insights about existing situations into preferred new ones. Buchanan and Margolin (1995) subscribe to this ethos and posit that 'existing impossibilities' may be interpreted as merely a limited imagination, which can be abated through design thinking. Designers further their 'thinking' by 'doing', which enables them to shift their explorations to exploitations by visualizing. They can then realize their thoughts and test their theories by engaging in iterative prototyping which enables them to translate their thinking into an embodied work of practice.

Design is taught in a range of areas in universities and straddles art, engineering and social sciences, and as such can be considered as an interdisciplinary practice in itself. It sits comfortably at the intersection between engineering and arts, but 'thinks' differently to art and to science. Designers can be promiscuous in their approach to research, drawing on a range of methodologies as they see appropriate to justify their outcomes (Maxcy 2003; Koskinen and Krogh 2015). This approach is in contrast to scientists who favour a singular controlled research methodology, and Gaver et al (2003) contend that design's mixed approach can leave it at loggerheads with scientific methodologies. The dynamic research processes in design seek to build up banks of ideas, which is in contrast to the critical thinking methodologies used by scientists who prefer to break their ideas down to find solutions. Science is driven by data and its linear research processes are concerned with adding to existing knowledge, and although its analytic nature explains new and existing phenomena, it cannot explain the qualitative novelty (Ziman 2000) gained through imagination and lateral exploration. The reasoned approach that scientists adopt using factual datasets from which they can deduct, is in stark contrast to designers' inductive thoughts which tease out a number of hypotheses. The different thought processes, research methods and semantics between both disciplines highlights a chasmic gap between them, which can make collaborating challenging. In Tim Brown's article on 'Design renews its Relationship with Science' (2011), he speculates- "If scientists were more comfortable with the intuitive nature of design, might they ask more interesting questions?" and 
yet despite their differences, both have curiosity in common and enjoy open-ended inquiry. However, scientists maintain that designers are often too anecdotal in their approaches and too hasty in coming to conclusions, and these contrasting approaches to inquiry can often cause creative tensions between disciplines in multidisciplinary teams, leading to disharmony and conflict in a co-design process. Fashion designer, McCann (2008) expresses the challenges she encountered with scientists during her interdisciplinary clothing research on Active Ageing. She acknowledges that emerging technologies can be confusing for clothing designers to understand, whilst noting that electronics and medical experts lack critical understanding of textile technology. She advocates finding commonality in 'language' and vision between disparate disciplines to facilitate understanding in interdisciplinary projects. Kirton (2004) argues that where understanding exists, conflict can be reduced, trust can be promoted and group effectiveness is enhanced. His Adaption-Innovation Theory describes a continuum with 'adaptors' at one end, who seek to improve on existing solutions by doing things better, and 'innovators' at the other end, who seek to find new solutions by doing things differently. $\mathrm{He}$ asserts that adaptors prefer order and structure and work effectively over longer periods of time, whereas innovators are less concerned with order and are more inclined to work in shorter dynamic bursts, which may appear undisciplined to others in the group. The breadth and divergence of innovators' creativity means they need to enlist the support of others to realise their ideas, and in contrast, adaptors prefer the stability of a dependable group rather than a larger network. Kirton concludes that innovators will seek solutions beyond their disciplinary boundaries. The traits identified by him can be mapped to scientists (adaptors) and designers (innovators), and his conclusions concur with the argument made in this paper that fashion and textile designers' thinking processes render them well placed to research, develop and deliver innovative solutions across disciplines. Rust (2004) and Peralta and Moultrie (2010), highlight the important contribution that design can make to science and technology, and current thinking in science is slowly beginning to acknowledge the advantages that collaboration between disciplines can bring (Bruns 2013). This welcomed shift in perspective suggests a deviation in traditional disciplinary thinking and the emergence of a new understanding between disciplines which can open fresh opportunities for design and science to collaborate. It resonates with calls from Rust (2007 pg.12), and Bracken and Oughten (2006 p.371) for a 'shared formal language' and Collins et al (2007, p.657) proposal for a 'Trading-Zone' at the intersection between disciplines where common semantics can be developed. When this occurs then innovative, new knowledge can be created. A prime example is 'Catalytic Clothing' (Storey and Ryan, 2011), a conceptual collaboration between a fashion designer and a scientist, resulting in the creation of a dress infused with a photocatalyst which breaks down air-borne pollution using light. The premise is that one day everyone could be collectively contributing to cleaner cities by walking around their environment with impregnated clothing. 
The ambiguity in IDR methodologies and lack of quantifiable metrics can be particularly challenging for scientists to accept; there are no metrics to quantify serendipity and curiosity, and committing to a research project where a key part of the process is to change the mind-set of the research group based on intuition, is at best uncomfortable for scientists. IDR calls for those who can work effectively within a dynamic environment and requires those who display an 'indifference to boundaries" (Whitfield, 2008, pg.872), and who can "jump knowledge together across disciplines" (Wilson 1998, p.8) to find commonality in practice. Central to this paper is the argument that the abilities of fashion and textile designers to adapt their practices and think speculatively about future possibilities render them well qualified to lead the IDR process.

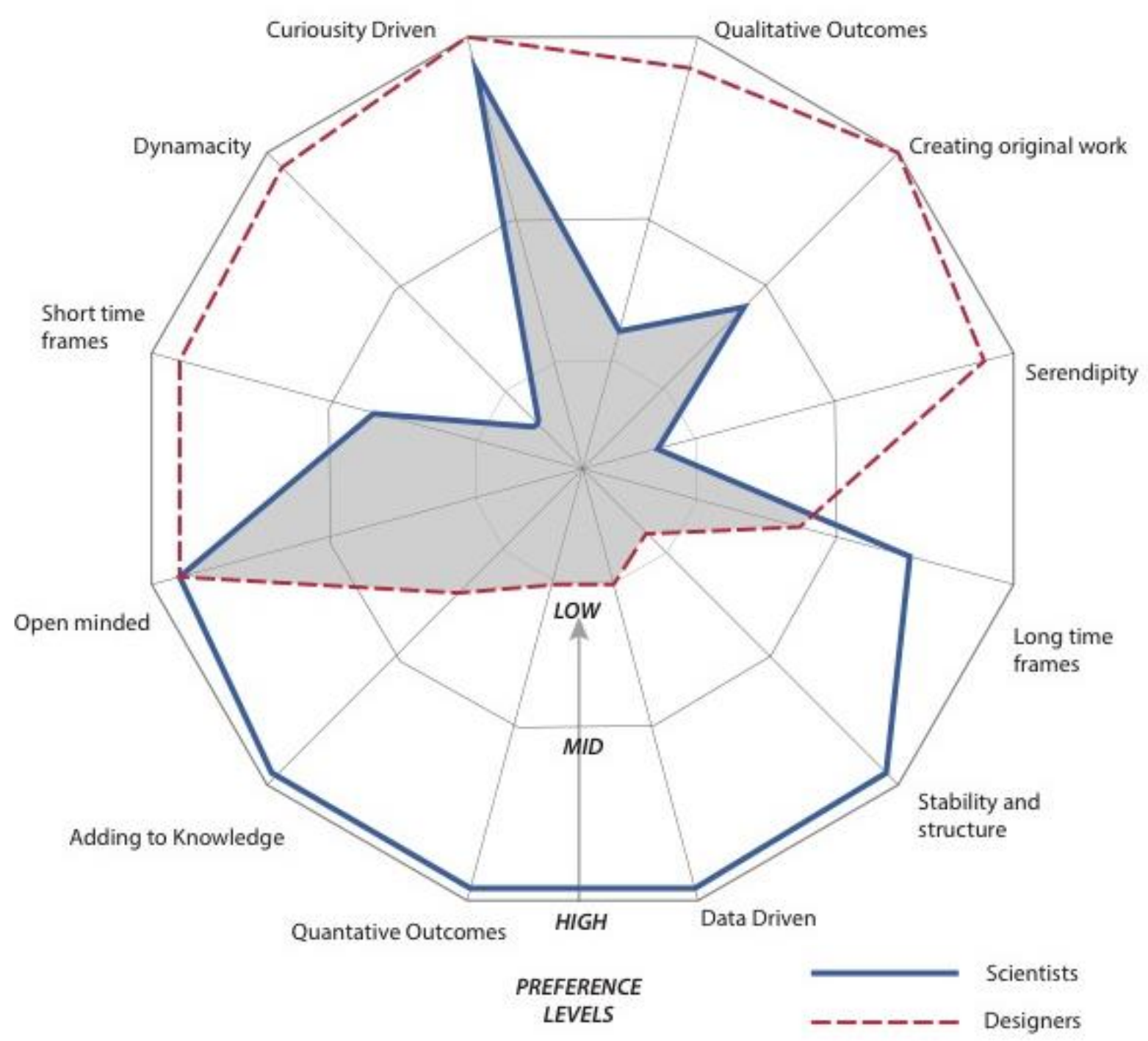

Figure 1. Differences in thinking and operational preferences of designers and scientists (Visualisation by Coulter 2017) 
Lyall et al (2015) emphasise the importance of setting boundaries for interdisciplinary research at the scoping stage and stress that these should not be established based on disciplines alone, but rather considered by a boundary that facilitates a creative approach. Figure 1 offers an empirical illustration that graphically maps the differences in thinking and operational preferences of designers and scientists. It shows how far apart they are in their preferences for dynamicity and stability, highlighting where boundaries need to be crossed and where commonalities such as open-mindedness and curiosity exist.

\section{Design Research Methodologies: Co-design, Speculative Design and Scenarios}

Designers have at their disposal, many qualitative methodologies to bring about interdisciplinarity in their research practice and one such example is co-design, which refers to a methodology requiring "creative cooperation during design processes" (Steen et al 2011). Sanders and Stappers (2008 p.2) interchange the term co-design for co-creation and define it as "any act of collective creativity that is shared by two or more people." The shared understanding across disciplines enables the production of co-created knowledge to achieve common objectives in the development of new products, and it is well documented that increasing shared understanding has a direct correlation to successful outcomes (Kleinsmann and Valkenburg 2008). Although there are many ideals associated with co-design, the rationale for co-design means that it is not typically understood from a science or engineering perspective, where practices are radically different (Steen et al 2013), and this can lead to barriers when participants or stakeholders are 'non-designers'. Co-design has multiple factors which contribute to, or inhibit its success and the lack of understanding between stakeholders, position and influence that stakeholders have within their respective organisations, and the value placed upon the project relative to all stakeholders collectively add to the complexity in achieving the project objectives. Co-design is only recently beginning to achieve validity and impact as a methodology, and Sanders and Stappers connote that previously it has been viewed as an academic activity with little or no relevance for industry. This is primarily because industry typically view investment in such research as a costly venture, with limited significance and they associate the speculative nature of research with risk. However, this view is changing as design begins to become accepted as a methodology to tackle emerging complex challenges, and industries and universities seek to collaborate to find novel ways to address these issues (Sanders and Stappers 2008). There are relatively few examples demonstrating textile- or fashion-led, co-design projects involving scientists and industry, which in itself is an indicator of the challenges of working across disciplines and with industry. The E-Co Challenge Project (Tyler et al 2006) illustrates how a collaborative approach with textile designers and engineering 
industrial partners enabled new product development, with cost savings and reduced time to market. Toeters et al (2013) writing about the Dutch Textile industry, but recognizing the challenges faced globally by this industry, suggest that the high degree of knowhow, focus on cost and a high level of competition render it particularly challenging for the textile industry to be receptive to the idea of interdisciplinary collaboration. In response to this, they created a platform for open innovation and collaboration called Creative Research Industry Science Project (CRISP 2011), with the aim of strengthening the Dutch Creative Economy. The project comprises 3 universities and 60 industrial partners. One of their initiatives 'Smart Textile Services' (STS) saw them collaborate with textile designers, scientists and technologists across two universities, and illustrates how the textile industry can benefit from interdisciplinary knowledge. As universities evolve to become more entrepreneurial, and academia forms new alliances with industry that go beyond consultancy, and where longer strategic solutions are sought, then creative problem solving can play a critical role in developing applied, interdisciplinary research which responds creatively to the changing needs of industry.

Speculative Design (SD) is a relatively new approach to design research, offering a novel method where designers use their visionary thoughts to scaffold ideas, enabling them to speculate about the future. They transform their inspirations into outcomes, maintaining that they can metamorphose existing situations into desirable new ones. Tina Gorjanc, a selfdescribed 'speculative scenario fashion designer' merges fashion and textile design with biotechnology and typifies how the next generation of hybrid fashion and textile designers might evolve. Designers skilled in SD, consider technological and social situations that don't yet exist (Dunne and Raby, 2013) in response to complex and abstract notions, postulating about how something could be in the future. They thrive in an ambivalent environment, and play a valuable role in bringing focus to new trends and ideas in science, and applied technology (Malpass (2013). Although abstract in nature, SD offers a useful methodology for creating ideas, as well as tangible outcomes, however its open-ended nature means that it can be mistaken for a conceptual art form by those who do not understand the fundamental differences between art and design. The process may seem particularly vague to scientists, and this makes it challenging to introduce SD into projects where scientists are integral to the research. However, SD is not as crude as pure conjecture, and Dunne and Raby insist that it is not as unreliable as forecasting or predicting. SD goes beyond trend-spotting techniques, and is more than a radical design process. Fairburn et at (2016) offer some novel examples which illustrate the value and potential of speculative design in textile research. A review of Critical Design at the Royal College of Art (2014) and its impact on design and science, examines how problem-solving can be approached from a fresh perspective to take advantage of emerging science and technologies within their social settings and cultural contexts. The review articulates through 
examples, how these may be utilized in novel ways. Smitheram (2016) uses speculative design approaches in her research to question perceived notions of textile and surface in a bid to consider potential futures for fashion, and she reimagines textile surface designs as digital interfaces. Auger (2013) argues that speculative design can be used in two ways: either to enable designers to think about the future, or to evaluate current practice and reapply what already exists in a new way. One of the key advantages of adopting an SD approach to research is that it eliminates the commercial pressure of trying to ensure that an idea or product is brought to market. However, Auger warns that contemplating ideas too far into the future is not useful in enabling designers to engage an audience who may not be able to connect with the futuristic possibilities suggested. Dunne and Raby move beyond pragmatic logic in their approach to SD and iteratively ask "what if?" as a probe to explore new concepts and imagine the future (Dunne and Raby, 2013; Ramirez et al 2015). This paper contends that in order for designers to harness the imaginative concepts inspired by SD, they need to conflate perspectives from science and design, and where appropriate involve industry and end users to create a co-design approach. Introducing a speculative element to a co-design model presents a useful framework for exploring new ideas, practices, projects and knowledge. This can result in a perceptive confluence of design, technology and science and culminate in unique transdisciplinary experiences and outcomes.

Introducing 'scenarios' into the design process enables designers to bring a holistic approach to problem solving. Stories about end users' experiences, whether actual or plausible present a valuable opportunity for designers to gain understanding of a problem from users' perspectives. The practice of focusing on past situations to improve future situations, acts as a conceptual bridge between current and imagined futures, and offers 'hybrid realities' (SchulzSchaeffer and Meister 2017). Scenarios are particularly useful where ethical challenges arise in engaging directly with a vulnerable targeted demographic, for example, elderly or very young communities. Fleshing out traits of a persona as part of a scenario can create a rich narrative, and enable a user centred-design problem to be more fully explored (Albinsson and Forsgren 2005). Scenarios can be both fixed and fluid, abstract, written from many perspectives and easily revised (Carroll 2000), and these fluctuating factors can appear flimsy to scientists engaged in co-design projects, who are challenged by the shifting and notional nature of this methodology. Similar to SD, the anecdotal perspective and perceived abstrusity of Scenarios can leave 'non-design' partners in co-design projects such as scientists or industrial partners, frustrated and disengaged from the process. This calls for careful and sustained planning by the designers, and face-to-face discussion at the outset of a co-design project to develop a shared understanding. 


\section{Academic-Industrial Partnerships}

Collaborative partnerships between academia and industry (A-I) have the potential to be powerful drivers for economic growth, and they display different characteristics from interdisciplinary partnerships between academics (A-A). The two are culturally divergent with very different missions and agendas, and industry's prime focus on sustainability and economic growth leaves it less receptive to the creative thinking processes of SD or Scenarios. Designers who can strategically place an industrial focus on SD and Scenario methodologies are more likely to produce conceptual briefs that will win business. However, as blue-sky approaches are not easily understood by industry, the impetus needs to come from the designer to champion SD and Scenarios as valid methodologies in co-design to gain the confidence of industry. SD in particular is a high-risk strategy to adopt with industrial partners who may not understand the designer's methodologies, or fully buy into the SD ethos. It does, however as Auger suggests, offer a useful strategy to re-evaluate current practice in a new way, which if well managed can bring successful new paradigms and relationships between design, science, technology and industry.

\section{Frameworks, Methodologies and Processes}

The discussion thus far has presented ideas and challenges associated with interdisciplinary practices, and perspectives on modes of interdisciplinary research, co-design methodologies, drivers and project focus to provide context to the research. Table 2 pulls these themes together and captures how they map to the two research case studies outlined in the paper. The Table highlights the different objectives and agendas of each project and shows that co-design and interdisciplinarity were key to both.

\begin{tabular}{|c|c|c|c|c|c|c|}
\hline $\begin{array}{l}\text { Case } \\
\text { Study }\end{array}$ & $\begin{array}{l}\text { Research } \\
\text { Mode }\end{array}$ & $\begin{array}{l}\text { Design } \\
\text { Methodology }\end{array}$ & Driver & Partnership & Focus & Outcome \\
\hline $\begin{array}{l}\text { Farm to } \\
\text { Fashion }\end{array}$ & $\begin{array}{c}\text { Cross-disciplinary } \\
\text { to } \\
\text { Interdisciplinary }\end{array}$ & $\begin{array}{l}\text { Speculative } \\
\text { Co-Design }\end{array}$ & $\begin{array}{l}\text { Curiosity } \\
\& \\
\text { Outcome }\end{array}$ & $\begin{array}{l}\text { Academic- } \\
\text { Industry }\end{array}$ & Industry & Product \\
\hline $\begin{array}{l}\text { Ageing } \\
\text { Mobility }\end{array}$ & $\begin{array}{l}\text { Multidisciplinary } \\
\text { to } \\
\text { Transdisciplinary }\end{array}$ & $\begin{array}{l}\text { Speculative } \\
\text { Co-Design } \\
\text { \& Scenario }\end{array}$ & Curiosity & $\begin{array}{l}\text { Academic- } \\
\text { Academic }\end{array}$ & Research & Prototype \\
\hline
\end{tabular}

Table 2. Case Studies mapped across key themes 
The case studies demonstrate interdisciplinarity and methodologies in co-design, and both exhibit speculative elements to varying degrees, dependent on the intended outcome. The situational and environmental factors which contributed to their success are discussed. The case studies highlight how all stakeholders engaged in design thinking methodologies, which enhanced creativity and innovation, and enabled them to become partners in the design process. Although the approximate timeline from inception to completion in each project was similar, Figure 2 summarises the division of time, and highlights similarities in initial project planning times and contrasting timeframes in delivery and execution. This was relative to the industrial nature of the Duck Farm project and the research nature of the Ageing project.

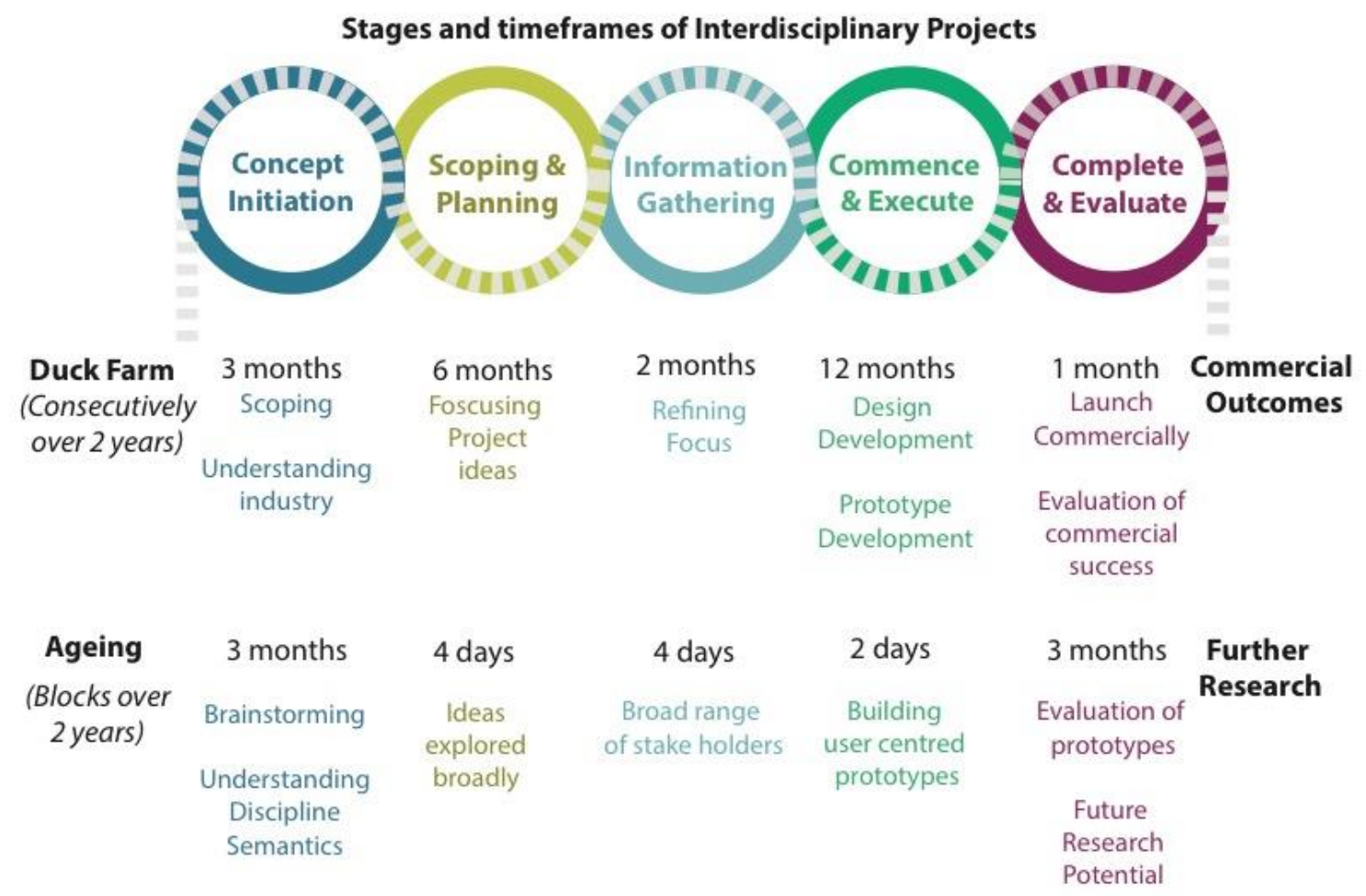

Figure 2. Timeframes of Case Studies

\section{Case Study 1: Farm to Fashion}

This research project offers an example of an A-I collaboration between two disparate sectorsfashion and food science. The research mode, thinking style, driver, focus and outcomes of the research have been defined in Table 2. The academic partners were from a fashion design 
discipline, and the industrial partners were duck farmers who managed a family run business, established more than 50 years ago. The business specializes in scientific methods of diversified farming and its core business is duck breeding, egg production, hatching and processing. The processes in food farming are meticulous and precise, and the Company operates under strict EU food science regulations. It wished to improve sustainability and reduce the waste disposal costs of animal bi products (down and feathers), which had to be incinerated off site, incurring ongoing costs, and sought the support of Ulster University to solve this problem. The idea of bringing two unrelated industries together is a phenomenon that has emerged over the past twenty years. Referred to as 'Industry Fusion' (Bierly and Chakrabarti, 1999), the term explains the expansion of sectoral boundaries of industries to include new products or services for other sectors, which may be related or unrelated. Whilst there are many ideals associated with industry fusion, the challenges are immense and the pressure to compete in global markets, within a saturated industry, and against cheap off-shore labour have made this unachievable for many small companies. Although cross-sectoral, industrial collaboration is precarious, it has the potential to create new, added-value products, and Davenport et al (2006) argue that it has become a model to respond to the emerging complex and dynamic innovation economy. In the context of this research, where there were no existing synergies between the two sectors the project was considered cross-sectoral and cross-disciplinary. The idea of the duck farm business extending its defined industrial boundaries to an unrelated market was a radical concept. The industrial partner was broadly receptive to any new idea that would result in reducing waste disposal costs and so a speculative design methodology, which was mindful of the need to consider 'near future products' (Auger 2013), was proposed by the designers, and diverse ideas around what could be done with waste bi-product were considered. A series of co-design workshops with a highly speculative approach informed the research to ensure that no ideas, markets, or end uses were discounted initially. Early ideas speculated on the possibility of converting the duck fat to a wax barrier product to proof outdoor clothing, and the potential of extracting keratin from the feathers to produce a bio-fuel was also explored. The idea of using the down bi-product from the ducks to produce fashion sports clothing was risky, as the Company had no background in fashion design. With no knowledge of the market, product, supply chain or logistics associated with the fashion industry, and no understanding of the manufacturing processes and associated plant requirements to produce bespoke garments, the Company found it challenging to imagine this as a possible future-topresent outcome. Additionally, there was no identified unique selling point (USP) to differentiate the Company in entering a highly saturated market. Similarly, the designers lacked an understanding of the science methodologies required to process the down, or of the nanotechnology needed to incorporate antibacterial properties. A serendipitous opportunity arose during one of the speculative workshops with the farmer's wife who was a fine artist. As 
part of the 'what if' iterations explored during the workshop, the team considered how her abstract artwork could be incorporated into the product. A Designers Sandpit (Tate et al 2000) enabled the Company to become co-designers and they were invited to participate in hands-on experimentation with a long arm quilter at the University, exploring a range of ideas including quilting feathers to the outer surface of the garments for embellishment (Fig $3 a$ and $3 b$ ). Ultrasonic welding was explored to minimize the loss of down through the holes made in the cloth through quilting processes, and the artist's fine artworks were playfully engineered through digital processes and digitally printed on to silk (Fig 4 and 5).

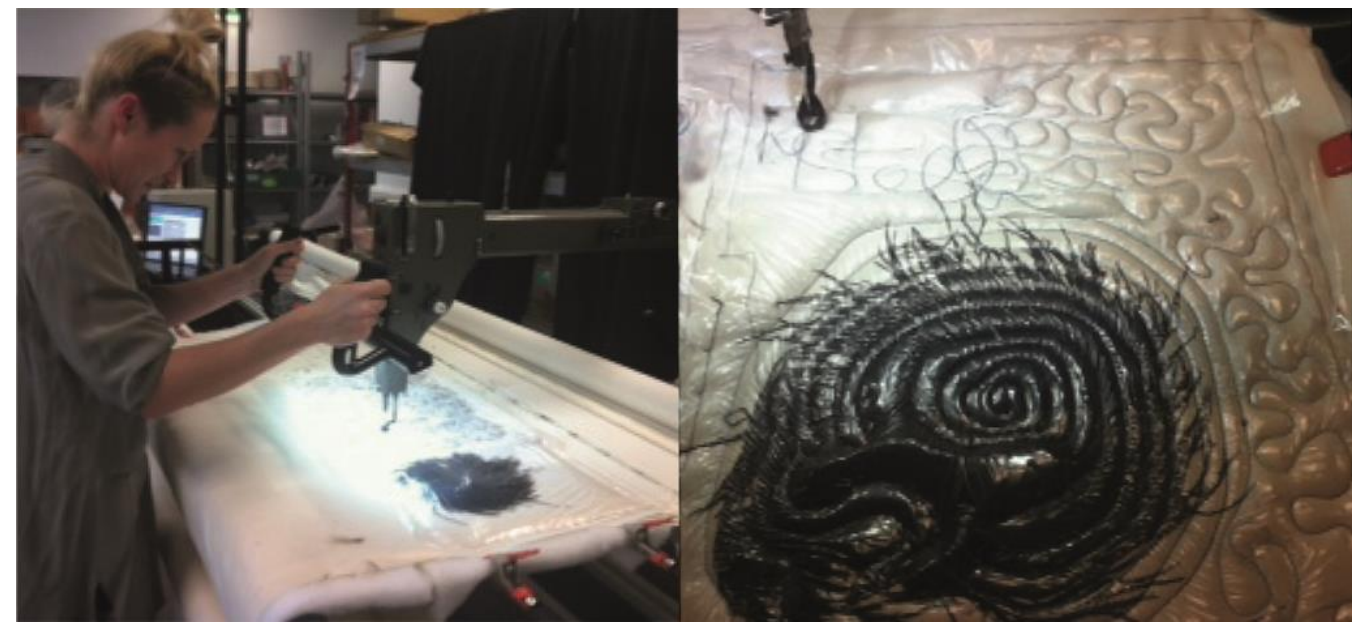

Figures 3a and 3b Designers Sandpit experimenting with Long-arm quilter 


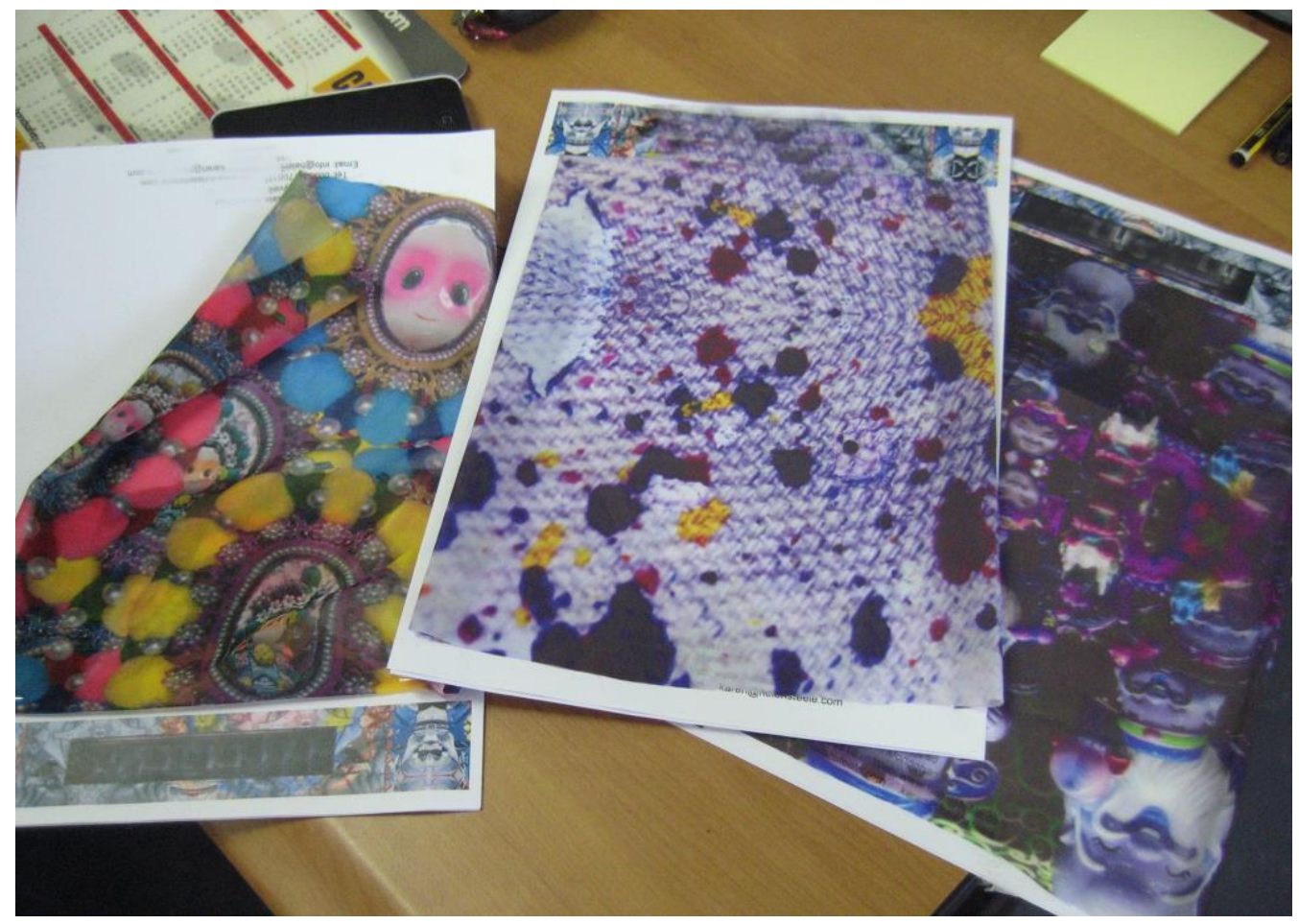

Figures 4 Engineered Digital Prints

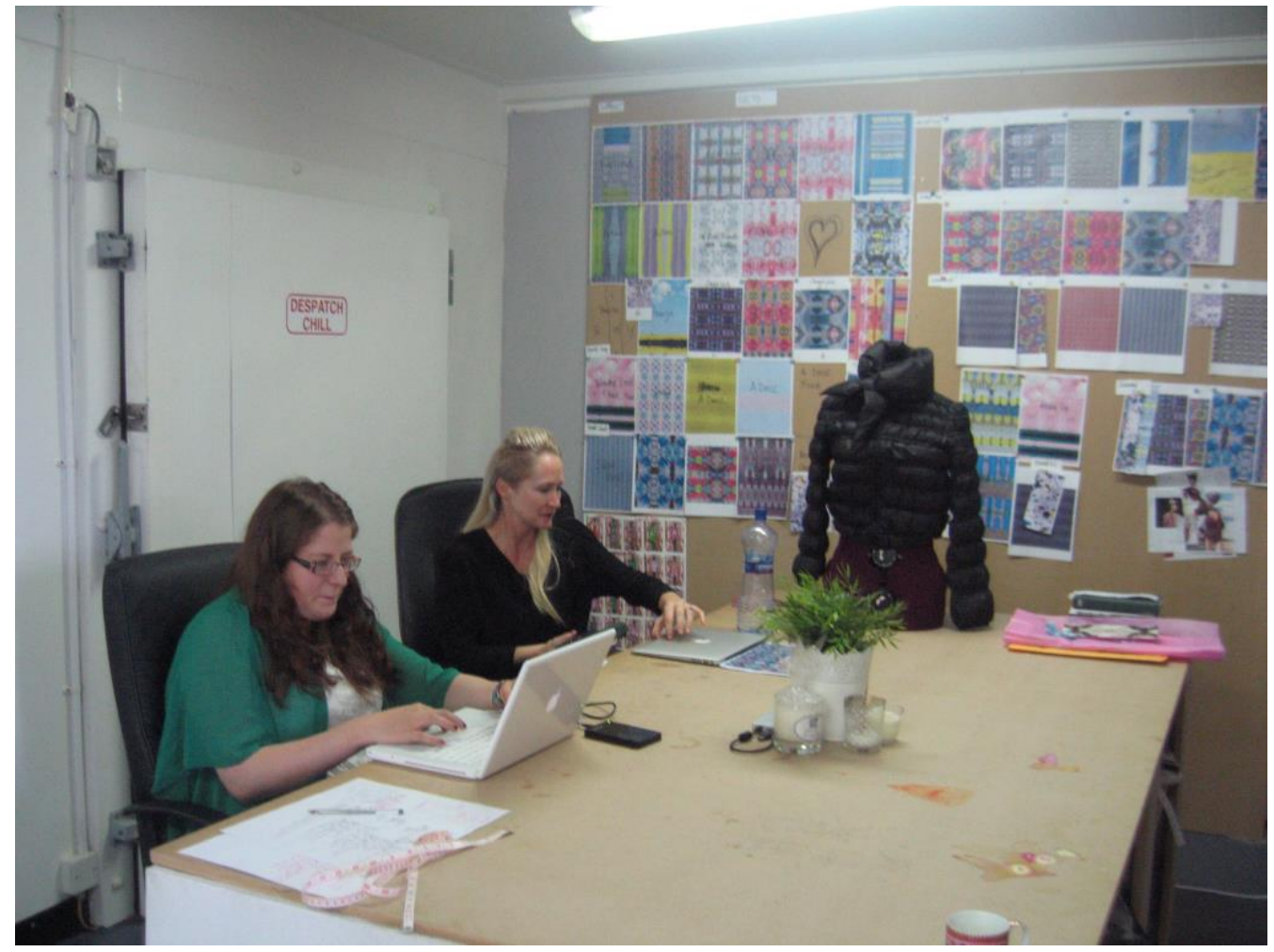

Figures 5 Engineering Works of Fine Art into original Digital Prints 


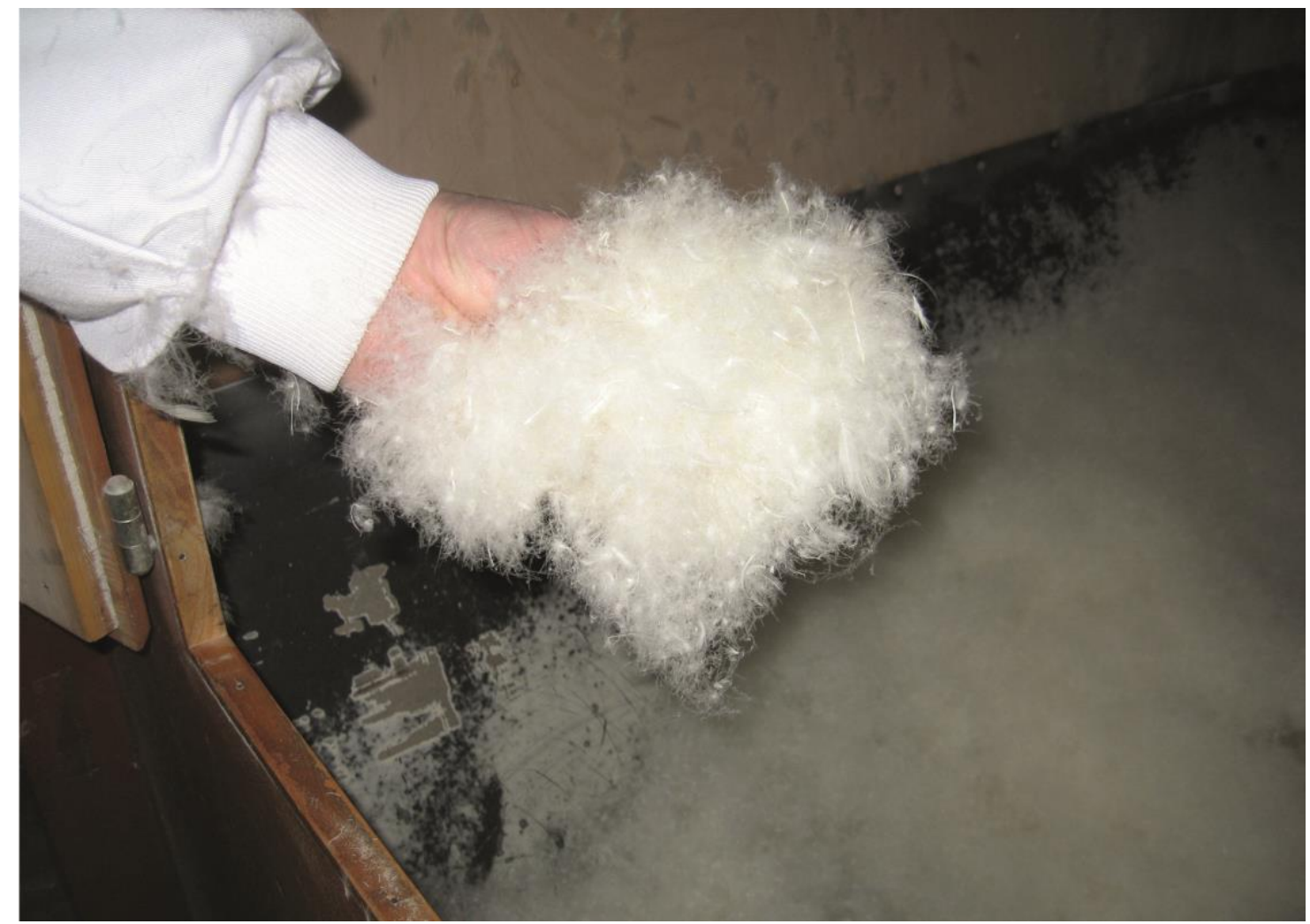

Figure 6 Scientist selecting down to chip

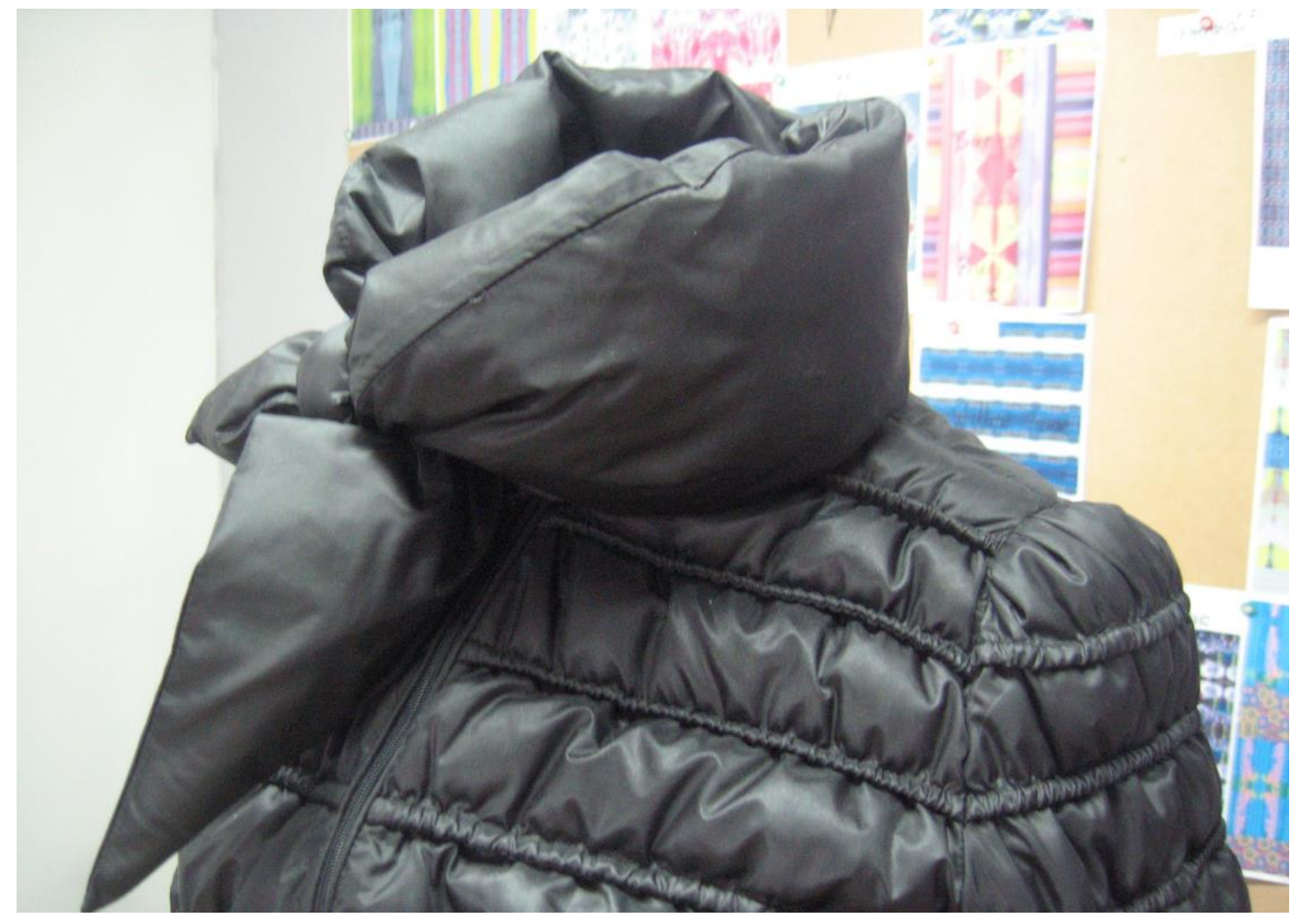

Figure 7 Prototype down jacket 
The opportunity to engage with hands-on experimentation enabled the Company to connect with the future possibilities and immersed them in the co-design experience. Fusing two disparate industries together is challenging, and with the end goal as it was in this project being driven by profit, speculation was kept within the boundaries of near-to-future, to ensure that it could be envisioned by all partners. The research took nine months to develop and the process was carefully managed to ensure that team members had the freedom to nurture trust and develop effective communication channels. The ambiguity of the research challenged the Company's established working practices and organisational processes however, the collaborative group remained open-minded, and bought into the speculative vision of the designers. This enabled trust to be established and the team made a conscious choice to share decision-making at every stage of the project. The expected outcome from the project was a portfolio of design concepts and initial prototypes. In reality, at the end of one year, a unique product range was designed and fully developed through innovative pattern engineering (Fig 7), and an international client base was established in The Middle East and Asia for the product, creating lucrative new markets for the Company. Waste disposal costs were reduced significantly, as there was no longer a need to dispose of animal bi-product off-site. The scientists worked on incorporating nanoparticles to chip the down, ensuring traceability anywhere in the world, and validating the high quality and authenticity of both the down and the design (Fig 6). These combined factors ensured that a premium price was achievable, and created a positive impact on the local economy and the regional supply chain. Sales increased in the first two years of trading, enabling some manufacturing to be re-shored to Ireland. Three years after the completion of the project (2015), the brand was exporting $70 \%$ of its production across 3 continents. 


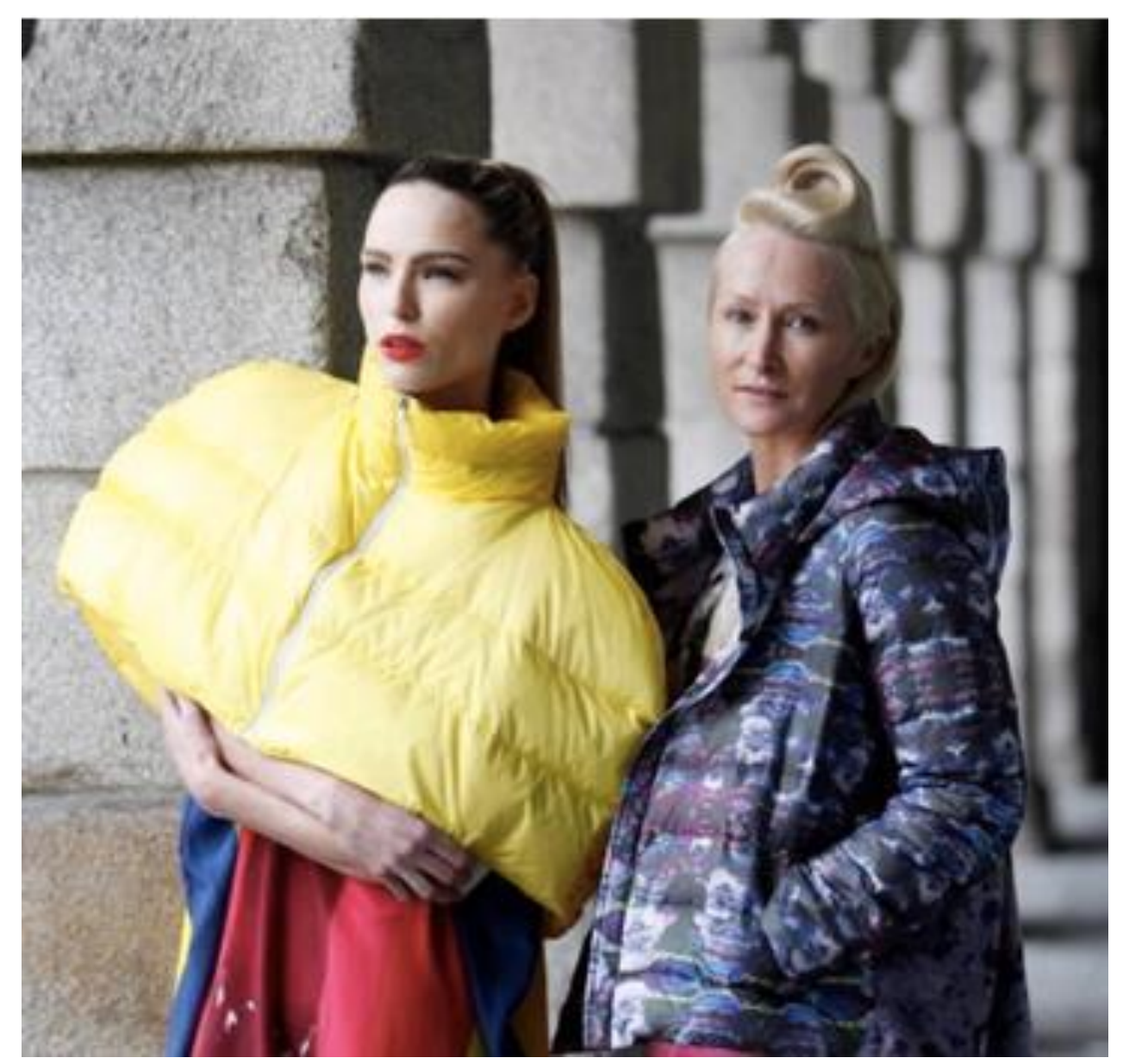

Fig 8 Innovative Designer Down Jackets produced as part of the interdisciplinary collaboration (Repo free)

\section{Reflections and Lessons from Case Study 1}

In reflecting upon the success of the project, the 'buy-in' from the industrial partner to the speculative methodology from the outset was significant. It enabled the company to think beyond the bounds of its sector and created a focus, driven by inquiry rather than exclusively outcome, as is the case with many industrial partnerships. Good communication and an appropriate time scale to develop the project enabled trust to be established and nurtured. An individual's need for dominance and power in an organisational context can be a key inhibitor in interdisciplinary research (Reich and Reich 2006) however, in the framework of this project an agreed, shared decision-making process mitigated against this, which built confidence in everyone's abilities and enabled mutual respect. A significant volume of new, non-discipline specific knowledge was gained by all participants. The academics gained new knowledge in nanotechnology, and the Company was able to develop a successful spin-off fashion business. The knowledge enriched follow-on projects in both sectors. Finally, there was 'serendipity', an unquantifiable synergy between the group, which was enhanced by the presence of the fine artist who had understanding of both the Company needs and the creative processes required 
to 'reform thought' (Montuori 2013) and envision an interdisciplinary perspective. The collective attitude to the inquiry and the co-created knowledge lifted the project from cross-disciplinary to interdisciplinary.

\section{Case Study 2 Co-Design of Mobility in Ageing}

This research project funded by the Arts and Humanities, Research Council (AHRC), was primarily an A-A collaboration over two years, with expertise spanning four partner universities and incorporating some input from end users and an industrial fashion partner at the initial stage. The academic partners came from fashion design, product design, textile technology, computer science and engineering. The group considered a breadth of health and wellness issues at a co-design workshop, and took a highly speculative approach before conceptualizing the idea as mobility in ageing. Figure 9 shows how the groups thoughts were visually captured and highlights the difference in language and thought processes across disciplines. The figure shows that the scientist's thoughts centred on analytics: 'quantifying anthropometric data'; 'Speckled computing' 'Limiting factors of technology'; 'Analysis, understand, interpret'. The designer's thoughts in contrast were concerned with qualitative observations: 'Desire'; 'Ways of conceiving the body; 'fidgeting as indicator of poor fit'. Table 2 summarises how the work undertaken mapped to the research mode, design methodology, driver, focus and outcome. The inquiry-driven process researched physical and emotional needs of older people with mobility issues, and explored alternative, highly conceptual solutions in which technical textiles and embedded sensors could be discretely incorporated into garments and products to support users in their daily living. The design thinking approach and SD methodology enabled the researchers to explore possible futures in the broadest sense. As the targeted end-user group were considered vulnerable, a scenario design methodology was adopted to identify three distinct personas and create new narratives, which helped to envision potential future experiences for the end-users. The personas were developed at a multidisciplinary co-design workshop, which followed the initial speculative workshop, and they offered reasonable representations of typical end-user demographics, incorporating their needs and lifestyles. This stimulated dialogue and debate amongst all researchers and created new interdisciplinary opportunities to share discipline knowledge and speculate further, while narrowing the focus to a targeted demographic. The researchers split into three interdisciplinary teams to explore the scenarios based around mobility in ageing (Fig 10), and visualised user-focused outcomes through rapid prototyping in a Maker Lab with CAM technology on hand to enable the 3D ideas to be realised in real-time (Fig 11). Outcomes were highly conceptual and included garments and products made with thermochromic and conductive textiles, with embedded heart, respiratory and temperature sensors. The outcomes from the prototyping workshop were at an early stage of market readiness and their precision and quality of execution were less important 
than their commercial potential, as the key purpose was to forecast future use, inform ideas for follow-on research and initiate new conversations with industry (Fairburn et. al 2016). The outcomes yielded opportunities for transformational, empathic end-user experiences. The combined knowledge and integrated efforts of the team ensured that the interdisciplinary research emerged as truly transdisciplinary.

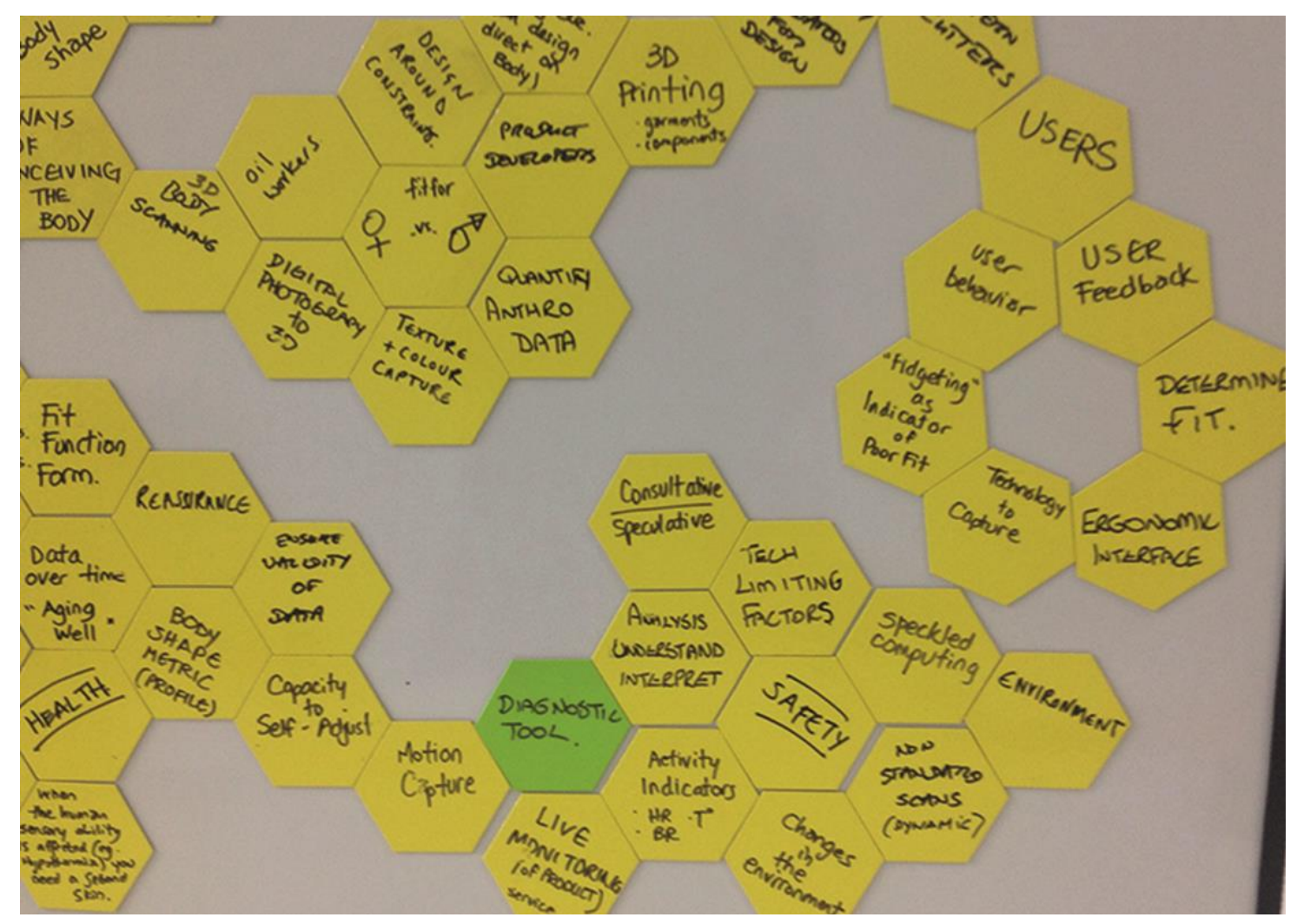

Fig 9 Design Thinking - Visualising thoughts at a Speculative Co-Design Workshop 


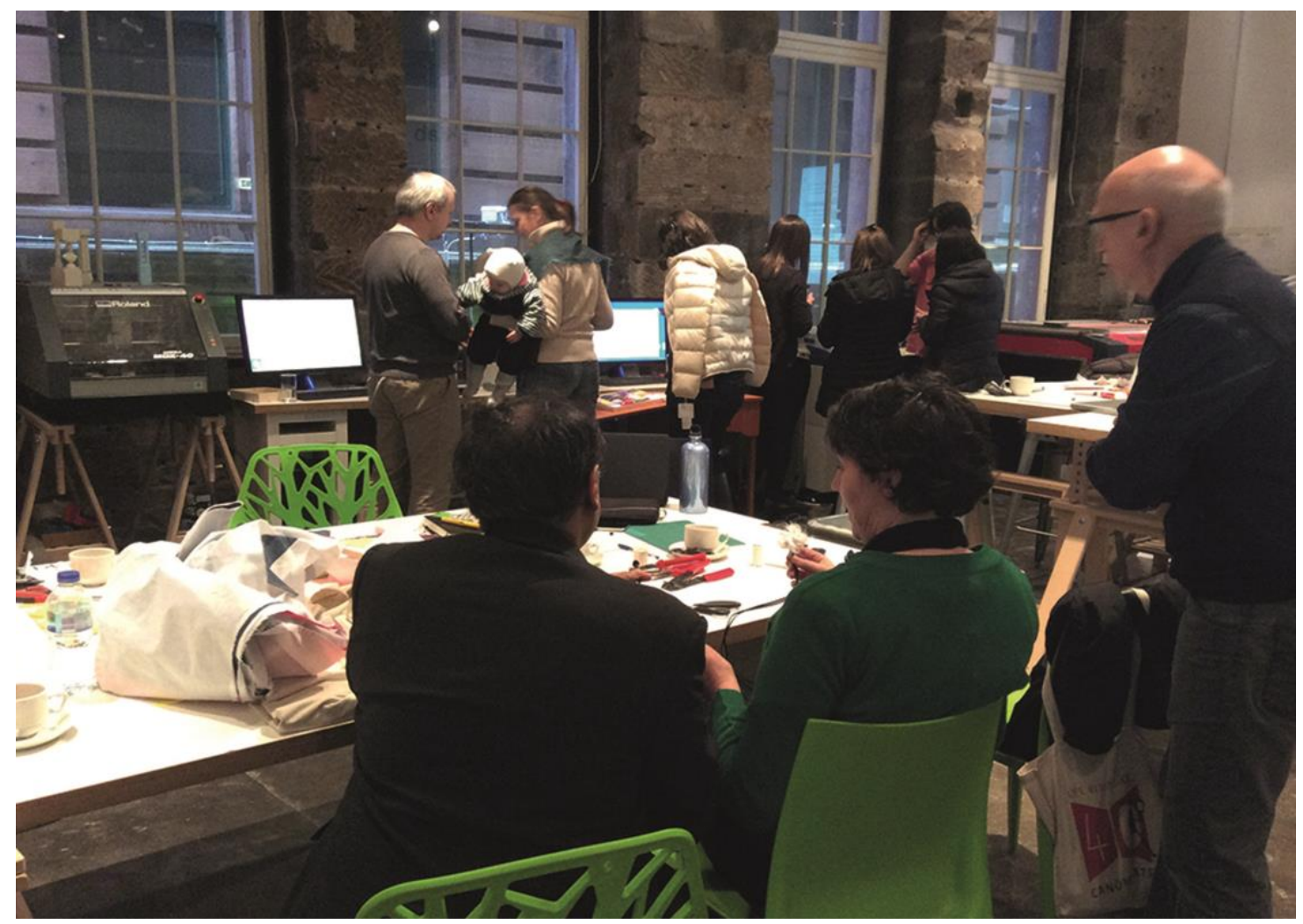

Fig 10 Interdisciplinary Teams of Scientists and Designers working on the Mobility in Ageing, Project

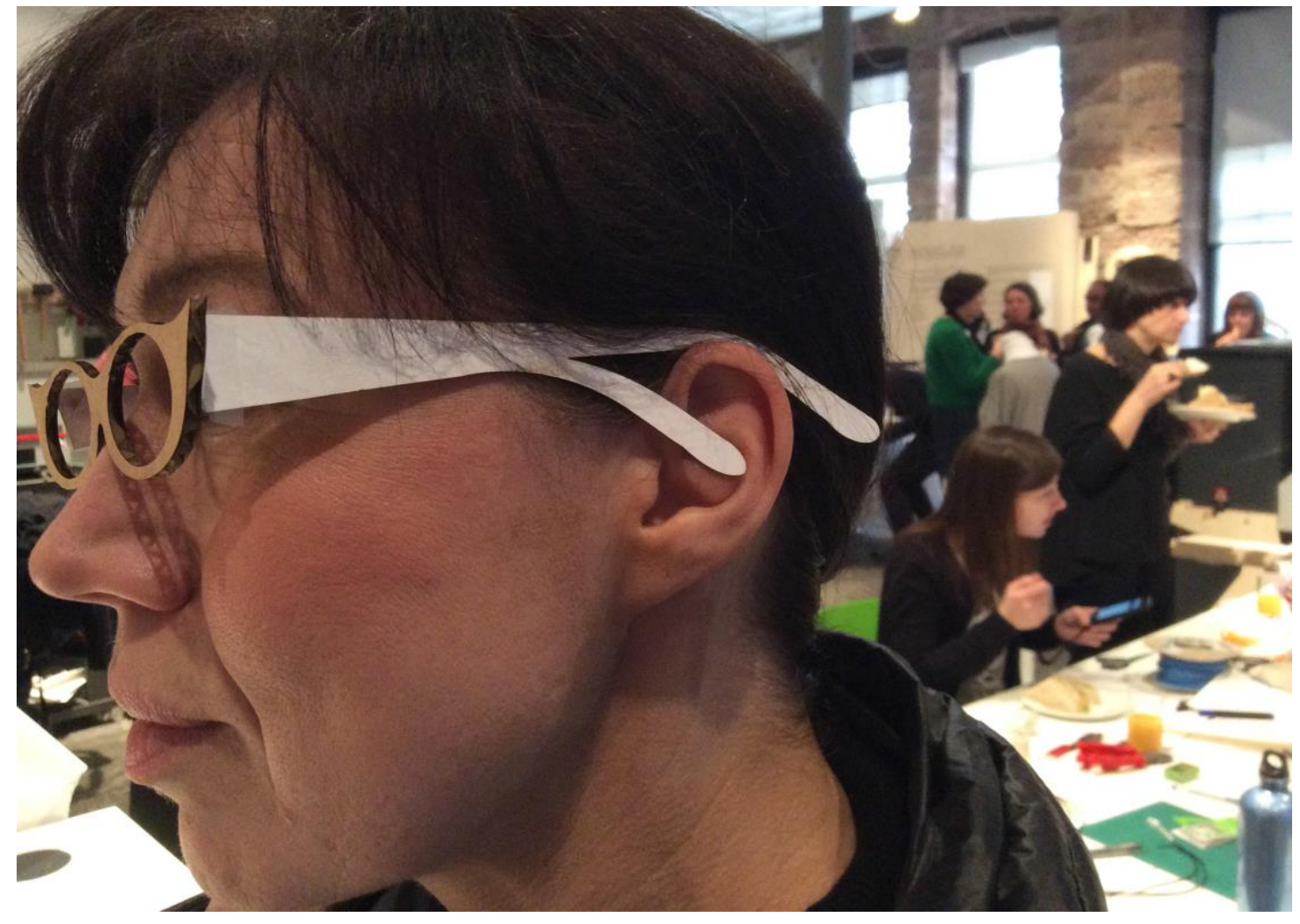

Figure 11 Speculative Co-Design Rapid Prototyping to realise ideas in real time 


\section{Reflections and Lessons from Case Study 2}

With no commercial or industrial constraints in the early part of the project, the process was highly speculative and freely explored future concepts for 'probable, possible and preferable' outcomes (Börjeson 2006), without consequence or judgment. The human-centered design thinking process (Maguire 2001; Sanders and Stapper, 2008) enabled empathic consideration for the end user, and the persona based scenarios contributed to the SD approach in capturing real situations and devising possible future outcomes. Having input from industry and users in the initial discussions brought some degree of 'grounding' to the SD process and ensured that explorations were not so futuristic that external stakeholders could not connect with the ideas. Participants from each discipline made a presentation to the multidisciplinary team at the beginning of the project to gain understanding of each other's disciplines however, it appeared that the early part of the project was dominated by fashion and textile designers, with the scientists seeming less integrated into the group. They found the design-led methodologies challenging, and observations showed that the scientists were less willing than the designers to 'boundary jump'. As the rapid prototyping and sensor needs became clearly identified in the project, the scientists engaged fully in the research and the project experienced interdisciplinary growth. The contextualised scenarios were particularly effective in stimulating dialogue across disciplines, and it was clear that sharing knowledge built trust and confidence amongst the group. Rodgers et al (2005) contend that to enhance the potential for successful outcomes that the research should hold equal interest for all disciplines involved, and they connote that no one discipline should appear closer to a solution at the beginning of the collaboration.

\section{Conclusion}

The two projects were quite different in their focus and outcomes however, there were common practices to each, which contributed to their success. Traits necessary for successful collaboration including open mindedness, willingness to learn from other disciplines personal empathy (Peralta and Moultrie 2010) were evident in both projects. Time was also a common factor and it was important for the researchers to have a pre-determined timeframe at the outset of each project, as IDR is difficult to sustain over an indefinite period. A long lead-time in scoping each project facilitated open dialogue between the disparate disciplines and established a shared understanding of each other's language and environmental constraints. The logistics of face-to face communication was very challenging however, it was crucial to building positive group dynamics, as was a willingness to accept that full understanding of each other's practices was not critical, but that sharing in the new knowledge created at the disciplinary intersections was essential. It is acknowledged that achieving this equilibrium is not as easy as the overarching ideal would suggest and there were frustrations and limitations - Scientists and 
designers are quite simply different! This paper has identified the commonalities and differences between fashion and textile designers, and scientists in a bid to understand how they may collaborate more effectively in the context of interdisciplinary work, and it has further identified factors for establishing a co-design design environment. Whilst it is clear that designers are focused on creating, and scientists are concerned with discovering, the case studies demonstrate there is a strong similarity in curiosity and the experimental approach to their respective disciplines, which suggests that they perhaps have more in common than they realise. The challenge for academic researchers is in building common environments and credibility with other disciplines to enable them to initiate collaboration, and this paper has established that textiles created a strong common denominator between disciplines in the case studies. It further argues that designers are well placed to be effective cross-pollinators and conduits between disciplines. The case studies demonstrate designers' indifference to boundaries, and their preference to work in environments where ambiguity is openly embraced. Designers exhibiting a willingness to take a 'leap of faith' across boundaries, alongside their intuitive ability to take advantage of serendipitous and unexpected events can support scientific methodologies and build new networks of practice. Their intuition enables them build holistic understanding by pooling knowledge from different disciplines and translating ideas across disciplinary silos, acting as 'transdisciplinary integrators and facilitators' Wahl and Baxter (2008 p1). The real potential for innovation occurs when all stakeholder in the co-design process begin to think beyond metrics, use curiosity and open mindedness as key drivers and take the leap together, in the belief that collectively they can make the future better than the present.

The author of this paper proposes to use the lessons learned from these co-design experiences to initiate further research which will engage designers with scientists, in collaborative co-design projects, through the common medium of textiles. Future work will explore more closely how such collaborations might be initiated by fashion and textile designers to connect design and science in real-world problems and develop new solutions to the mutual value of both disciplines, and to the benefit to industry.

\section{References}

1. Albinsson, L., \& Forsgren, O. (2005). Co-Design Metaphors and Scenarios-Two Elements in a Design Language for Co-Design. LAP, Kiruna.

2. Auger, J. (2013). Speculative design: crafting the speculation. Digital Creativity, 24(1), 11-35.

3. Bierly, P. and Chakrabarti, A.K., 1999. Managing through industry fusion. The Dynamics of Innovation. Springer, pp. 3-26. 
4. Bammer, G. (2016). Moving interdisciplinary research forward: Top down organising force needed to help classify diverse practices. Impact of Social Sciences Blog.

5. Blackwell, A., Wilson, L., Boulton, C., \& Knell, J. (2010). Creating value across boundaries: Maximising the return from interdisciplinary innovation. London: NESTA Research Report.

6. Briggs-Goode, A., Glazzard, M., Walker, S., Kettley, S., Heinzel, T. and Lucas, R., (2016). Wellbeing and smart textiles: reflecting on collaborative practices and the design process. Journal of Textile Design Research and Practice, 4(1), pp.63-83.

7. Bracken, L. J., \& Oughton, E. A. (2006). "What do you mean?" The importance of language in developing interdisciplinary research. Transactions of the Institute of British Geographers, 31(3), 371-382.

8. Brjeson, L., Hjer, M., Dreborg, K.-H., Ekvall, T., \& Finnveden, G. (2006). Scenario types and techniques: towards a user's guide. Futures, 38(7), 723-739.

9. Brown, T. (2011). Design renews its Relationship with Science. Retrieved from http://designthinking.ideo.com/?p=528 Retrieved Nov 2017

10. Bruns, H. C. (2013). Working alone together: Coordination in collaboration across domains of expertise. Academy of Management Journal, 56(1), 62-83.

11. Buchanan, R., \& Margolin, V. (1995). Discovering design: explorations in design studies. University of Chicago Press.

12. Carroll, J. M. (2000). Five reasons for scenario-based design. Interacting with Computers, 13(1), 43-60.

13. Collins, H., Evans, R., \& Gorman, M. (2007). Trading zones and interactional expertise. Studies in History and Philosophy of Science Part A, 38(4), 657-666.

14. Cox, G. (2005). Cox review of creativity in business: building on the UK's strengths. TSO.

15. Cross, N. (2001). Designerly ways of knowing: Design discipline versus design science. Design Issues, 17(3), 49-55.

16. Davenport, T. H., Leibold, M., \& Voelpel, S. C. (2007). Strategic management in the innovation economy: Strategic approaches and tools for dynamic innovation capabilities. John Wiley \& Sons.

17. Dunne, A., \& Raby, F. (2013). Speculative everything: design, fiction, and social dreaming. MIT Press.

18. Fairburn, S., Steed, J. and Coulter, J., 2016. Spheres of Practice for the Co-design of Wearables. Journal of Textile Design Research and Practice, 4(1), pp.85-109.

19. Feller, I. (2006). Multiple actors, multiple settings, multiple criteria: issues in assessing interdisciplinary research. Research Evaluation, 15(1), 5-15.

20. Gaver, W. W., Beaver, J., \& Benford, S. (2003). Ambiguity as a resource for design. In Proceedings of the SIGCHI conference on Human factors in computing systems (pp. 233-240). ACM.

21. Gibbons, M., Limoges, C., Nowotny, H., Schwartzman, S., Scott, P., \& Trow, M. (1994). The new production of knowledge: The dynamics of science and research in contemporary societies. Sage.

22. Hackett, E. J. (2005). Essential tensions: Identity, control, and risk in research. Social Studies of Science, 35(5), 787-826.

23. Heimdal, E. and Lenau, T., 2010. Physical tools for textile creativity and invention. DUCK Journal for Research in Textiles and Textile Design, 1(1), pp.1-14.

24. Huutoniemi, K., Klein, J. T., Bruun, H., \& Hukkinen, J. (2010). Analyzing interdisciplinarity: Typology and indicators. Research Policy, 39(1), 79-88.

25. III, P. E. B., \& Chakrabarti, A. (2001). Dynamic knowledge strategies and industry fusion. International Journal of Manufacturing Technology and Management, 3(1-2), 31-48.

26. Ito, J. (2016). Can design advance science, and can science advance design. Journal of Design and Science. MIT Press. Retrieved from https://www.pubpub.org/pub/designandscience?context=jods

27. Jensenius, A. R. (2012). Disciplinarities: intra, cross, multi, inter, trans. Retrieved from www.arj.no/2012/03/12/disciplinarities-2 
28. Kirton, M. (1976). Adaptors and innovators: A description and measure. Journal of Applied Psychology, 61(5), 622.

29. Kirton, M. J. (2004). Adaption-innovation: In the context of diversity and change. Routledge.

30. Klein, J. T. (1990). Interdisciplinarity: History, theory, and practice. Wayne state university press.

31. Klein, J. T. (1996). Crossing boundaries: Knowledge, disciplinarities, and interdisciplinarities. University of Virginia Press.

32. Klein, J. T. (2006). Afterword: the emergent literature on interdisciplinary and transdisciplinary research evaluation. Research Evaluation, 15(1), 75-80.

33. Klein, J. T. (2015). Reprint of "Discourses of transdisciplinarity: Looking back to the future." Futures, 65, 10-16.

34. Kleinsmann, M., \& Valkenburg, R. (2008). Barriers and enablers for creating shared understanding in co-design projects. Design Studies, 29(4), 369-386.

35. Koskinen, I., \& Krogh, P. G. (2015). Design accountability: When design research entangles theory and practice. International Journal of Design, 9(1), 121-127.

36. Lyall, C., Bruce, A., Tait, J., \& Meagher, L. (2015). Interdisciplinary research journeys: Practical strategies for capturing creativity. Bloomsbury Publishing.

37. Maguire, M. (2001). Methods to support human-centred design. International Journal of Human-Computer Studies, 55(4), 587-634.

38. Malpass, M. (2013). Between Wit and reason: defining associative, speculative, and critical design in practice. Design and Culture, 5(3), 333-356.

39. Maxcy, S. J. (2003). Pragmatic threads in mixed methods research in the social sciences: The search for multiple modes of inquiry and the end of the philosophy of formalism. Handbook of Mixed Methods in Social and Behavioral Research, 51-89.

40. Montuori, A. (2013). Complexity and transdisciplinarity: Reflections on theory and practice. World Futures, 69(4-6), 200-230.

41. Morgan, L. (2017) Interdisciplinary Textile Design Research for material innovation: Synthesising design, science and industry collaboration. Intersections: A conference exploring collaboration in Textile Design Research. September 13, 2017, Loughborough University

42. McCann, J., 2008. Design for ageing well: Improving the quality of life for the ageing population using a technology enabled garment system. In Advances in Science and Technology (Vol. 60, pp. 154-163). Trans Tech Publications.

43. Peralta, C., \& Moultrie, J. (2010). Collaboration between designers and scientists in the context of scientific research: A literature review. In DS 60: Proceedings of DESIGN 2010, the 11th International Design Conference, Dubrovnik, Croatia.

44. Ramirez, R., Mukherjee, M., Vezzoli, S. and Kramer, A.M., 2015. Scenarios as a scholarly methodology to produce "interesting research". Futures, 71, pp.70-87.

45. Reich, S. M., \& Reich, J. A. (2006). Cultural competence in interdisciplinary collaborations: A method for respecting diversity in research partnerships. American Journal of Community Psychology, 38(1-2), 1-7.

46. Rodgers, I., Scaife, M., Rizzo, A., Derry, S., Gernsbacher, M. A., \& Schunn, C. D. (2005). Interdisciplinary Collaboration: An Emerging Cognitive Science. Interdisciplinary Collaboration: An Emerging Cognitive Science.

47. Rust, C., 2007. Unstated Contributions-How artistic inquiry can inform interdisciplinary research. International Journal of Design, 1(3).

48. Sainsbury, D. (2007). The race to the top: A review of Government's science and innovation policies. [HM Treasury], London, UK.

49. Sanders, E. B.-N., \& Stappers, P. J. (2008). Co-creation and the new landscapes of design. Co-Design, 4(1), 5-18.

50. Schulz-Schaeffer, I., \& Meister, M. (2017). Laboratory settings as built anticipationsprototype scenarios as negotiation arenas between the present and imagined futures. Journal of Responsible Innovation, 1-20. 
51. Shrum, W., Genuth, J., \& Chompalov, I. (2007). Structures of scientific collaboration. MIT Press.

52. Smitheram, M., 2016. The hand of the cloth: An ontological and aesthetic unfolding through digital and virtual materiality(Doctoral dissertation, Auckland University of Technology).

53. Song, S., Dong, A., \& Agogino, A. M. (2003). Time variation of design "story telling" in engineering design teams. In DS 31: Proceedings of ICED 03, the 14th International Conference on Engineering Design, Stockholm.

54. Steen, M. (2013). Co-design as a process of joint inquiry and imagination. Design Issues, 29(2), 16-28.

55. Steen, M., Manschot, M. A. J., \& Koning, N. De. (2011). Benefits of co-design in service design projects. International Journal of Design 5 (2) 2011, 53-60.

56. Stember, M. (1991). Advancing the social sciences through the interdisciplinary enterprise. The Social Science Journal, 28(1), 1-14.

57. Stinson, E. (2016, March). MIT Media Lab's Journal of Design and Science Is a Radical New Kind of Publication. Retrieved from http://scholar.aci.info/view/1476b1d538930fb01bd/153629b61b500014c0d Retrieved Nov 2017

58. Strang, V., \& McLeish, T. (2015). Evaluating interdisciplinary research: a practical guide. Durham University Report.

59. Tate, S., Jared, G., Brown, N. and Swift, K.G., (2000), September. An introduction to the Designers' Sandpit. In International Design Engineering Technical Conferences and Computers and Information in Engineering Conference, ASME, Baltimore, MD (pp. 8487).

60. Tress, B., Tress, G., \& Fry, G. (2005). Integrative studies on rural landscapes: policy expectations and research practice. Landscape and Urban Planning, 70(1), 177-191.

61. Toeters, M., ten Bhömer, M., Bottenberg, E., Tomico, O. and Brinks, G., 2013. Research through design: a way to drive innovative solutions in the field of smart textiles. In Advances in Science and Technology (Vol. 80, pp. 112-117). Trans Tech Publications.

62. Wahl, D.C. and Baxter, S., 2008. The designer's role in facilitating sustainable solutions. Design Issues, 24(2), pp. 72-83.

63. Walker, S., Kettley, S., Downes, T. and Dias, T., 2015, September. Facilitating participatory practice for smart textiles. In Adjunct Proceedings of the 2015 ACM International Joint Conference on Pervasive and Ubiquitous Computing and Proceedings of the 2015 ACM International Symposium on Wearable Computers (pp. 521-526). ACM.

64. Wilson, E.O., 1998. Consilience: the unity of science. New York: Knopf, 171, pp. 182.

65. Walker, R. M. (2011). Globalized public management: an interdisciplinary design science? Journal of Public Administration Research and Theory, 21(suppl_1), i59.

66. Wyatt, J. and Brown, T., 2010. Design thinking for social innovation. Stanford Social Innovation Review. https://ssir.org/articles/entry/design thinking for social innovation Retrieved Nov 2017

67. Whitfield, J. (2008). An indifference to boundaries. Nature, 451(7181), 872-873.

68. Ziman, J. (2000). Real Science: What It Is, and What It Means. Cambridge: Cambridge University Press.

\section{Additional References}

1. MAKLab. http://maklab.co.uk/glasgow/

2. Royal College of Art: Ref Impact Case Study.

http://impact.ref.ac.uk/CaseStudies/CaseStudy.aspx?ld=44132

\section{Funding}

Ageing in Mobility Research funded by AHRC. Grant AH/K000640/1 
Farm to Fashion project funded by Intertrade Ireland

\section{Tables and Figures}

Table 1. Definitions of Modes of research practice

Table 2. Case Studies mapped across key themes

Figure 1 Differences in thinking and operational preferences of designers and scientists (Visualisation by Coulter 2017)

Figure 2 Stages and Timeframes mapped to Case Studies (Visualisation by Coulter 2017)

Figures 3a, 3b Designers Sandpit - experimenting with Long-arm quilter

Figure $4 \quad$ Engineered Digital Prints

Figure $5 \quad$ Engineering Works of Fine Art into original Digital Prints

Figure $6 \quad$ Scientist selecting down for chipping

Figure $7 \quad$ Innovative pattern engineering prototype jacket

Figure 8 Innovative Designer Down Jackets produced as part of the interdisciplinary collaboration (Repo free)

Figure 9 Design Thinking - Visualising thoughts at a Speculative Co-Design Workshop

Figure $10 \quad$ Interdisciplinary Teams of Scientists and Designers working on the Mobility in Ageing, Project at MakLab, Glasgow

Figure 11 Speculative Co-Design Rapid Prototyping to realise ideas in real time 